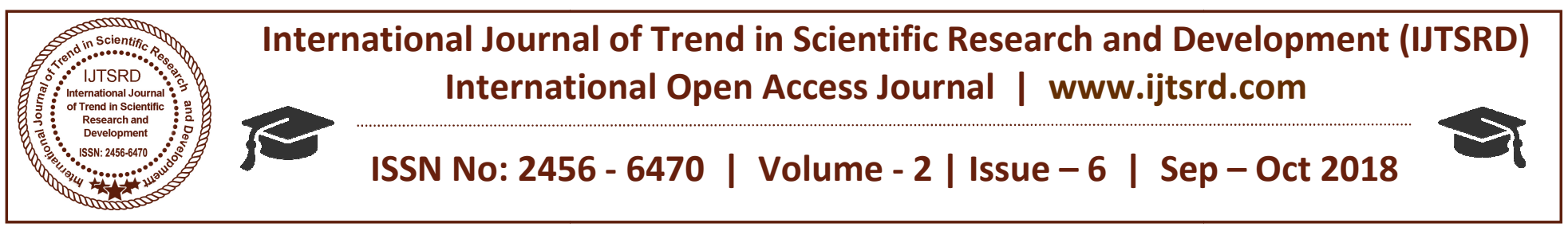

\title{
Responsibilities and Qualities of a Supervisor
}

\author{
Dr. K. Usha Rani \\ Assistant Professor, Department of English, \\ K. L. Deemed to be University, Vaddeswaram, Guntur, Andhra Pradesh, India
}

\begin{abstract}
Research plays a major role in all-round development of an individual. A supervisor is the key person in research. The principal role of the supervisor is to help students achieve their scholastic potential and to chair the student's Supervisory Committee. The Supervisor will provide reasonable commitment, accessibility, professionalism, stimulation, guidance, respect and consistent encouragement to the student. A supervisor assists the student with the selection and planning of a suitable and manageable research topic and is sufficiently familiar with the field of research to provide guidance and/or has a willingness to gain that familiarity before agreeing to act as a supervisor. The qualities of a supervisor are good communication. Ideal supervisors have good communication skills. In particular: good listening skills; the tendency to maintain an open dialogue about the project, its progress and problems; the ability to communicate in an open, honest, and fair manner about issues that arise as they arise. A Successful supervisor knows what is going on in their organization. He has knowledge about objectives and plans, their product, organizational hierarchy etc. It is necessary for him to store all this information otherwise they will not know where to look for
\end{abstract} information about all these matters.

Keyword: Accessibility, commitment, guidance, respect, stimulation

Research plays a major role in all-round development of an individual. A supervisor is the key person in research. The principal role of the supervisor is to help students achieve their scholastic potential and to chair the student's Supervisory Committee. The Supervisor will provide reasonable commitment, accessibility, professionalism, stimulation, guidance, respect and consistent encouragement to the student.

Supervisors should be available to help their students at every stage, from formulation of their research projects through establishing methodologies and discussing results, to presentation and possible publication of dissertations. Supervisors must also ensure that their students' work meets the standards of the University and the academic discipline.

\section{Some specific responsibilities of a supervisor:}

$>$ Assists the student with the selection and planning of a suitable and manageable research topic.

$>$ Is sufficiently familiar with the field of research to provide guidance and/or has a willingness to gain that familiarity before agreeing to act as a supervisor.

$>$ Is accessible to the student for consultation and discussion of the student's academic progress and research.

$>$ Responds in a timely and thorough manner to written work submitted by the student, with constructive suggestions for improvement and continuation.

$>$ Makes arrangements to ensure continuity of supervision when the supervisor will be absent for extended periods, e.g. a month or longer.

When necessary, assists the student in gaining access to facilities or research materials.

Ensures that the research environment is safe, healthy and free from harassment, discrimination and conflict.

$>$ Assists the student in being aware of current graduate program requirements, deadlines, sources of funding, etc.

$>$ Encourages the student to make presentations of research results within the University and to outside scholarly or professional bodies as appropriate. 
$>$ Encourages the student to finish up when it would not be in the student's best interests to extend the program of studies.

$>$ Acknowledges appropriately the contributions of the student in presentations and in published material, in many cases via joint authorship.

$>$ Assists the student to comply with any changes that need to be made to the thesis after the thesis or dissertation defence.

\section{Qualities of a Supervisor:}

\section{AVAILABILITY:}

Students value availability in their supervisors. This involves supervisors meeting with students regularly, setting aside adequate time for students, and being contactable through several media (e.g., email, phone) - particularly if they are not physically present.

\section{APPROACHABILITY AND RAPPORT:}

The ideal supervisor is approachable and works to establish a good rapport with their students.

\section{CONSTRUCTIVE FEEDBACK:}

Students see an ideal supervisor as one who provides feedback and criticism of their work that is constructive and prompt. In addition, students value consistency in the feedback given. Some valued consistency across time. This is often a sign that the supervisor and student share the same focus regarding the project. In addition, where more than one supervisor, is responsible for providing feedback, consistency between supervisors is important.

\section{EXPERIENCE \\ AND SUPERVISION:}

Part of being experienced and interested in supervision, a key quality of an ideal supervisor, is having a complete understanding of the requirements and process of completing a thesis. In addition, students value supervisors who consider the needs of particular subgroups of the student population (e.g., international students, those with children, those with disabilities, and those with cultural differences). It is important that supervisors recognise the individual supervisory needs of each student. These vary between students and between different stages of their studies.

\section{GOOD COMMUNICATION:}

Ideal supervisors have good communication skills. In particular: good listening skills; the tendency to maintain an open dialogue about the project, its progress and problems; the ability to communicate in an open, honest, and fair manner about issues that arise as they arise; and making expectations clear with regard to matters such as the process of completing a PhD or Master's thesis, budget considerations, and the role each party must play in performing the project research.

\section{INTEREST AND ENTHUSIASM:}

Students portrayed the ideal supervisor as someone who is interested and enthusiastic about the student's work. This is achieved by supervisors who are positive, empowering, motivational, and committed. Such supervisors are often in the vicinity of their students and are likely to show an interest in the student's progress.

\section{INTEREST IN THE STUDENT'S CAREER:}

Ideal supervisors are likely to show an interest in the student's career. They help to provide support for the establishment of the student's career in several ways. These include having good contacts and introducing students to their network of colleagues, looking out for and informing students of conferences and seminars relevant to their research and career, and encouraging and facilitating the publication of the student's research.

\section{KNOWLEDGE AND EXPERTISE IN THE FIELD SURROUNDING:}

The $\mathrm{PhD}$ Ideal supervisors are those who have expertise in the field surrounding the student's research. Students value highly a supervisor who can use their knowledge of the area to understand and demonstrate how the student's research topic fits within the wider field.

\section{PROVIDES DIRECTION AND STRUCTURE:}

The ideal supervisor is perceived to be one who provides an appropriate amount of direction and structure to the student's research project. The ideal supervisor helps to encourage good work habits in the student, thereby helping the student a little when required. Such a supervisor is informative and helpful when it comes to areas of uncertainty.

\section{SUPPORT:}

Supportiveness is the quality that $\mathrm{PhD}$ students value most highly in supervisors. This involves supervisors being encouraging, mentoring, and aware that students' lives extend beyond the PhD. Supportive supervisors make an effort to understand how the 
student prefers to work. In addition, such supervisors attend to the student as a whole person, rather than purely as a research student.

\section{CONCLUSION}

A Successful supervisor knows what is going on in their organization. He has knowledge about objectives and plans, their product, organizational hierarchy etc. It is necessary for him to store all this information otherwise they will not know where to look for information about all these matters.

He also possesses technical knowledge such as production technology, basic principles of management like planning, organizing, directing, motivating and controlling. But these are not the only qualities and skills a manager, leader or decision maker needs to be successful.

\section{REFERENCES}

1. Whisker, Gina, The Good Supervisor, Supervising Post Graduate and undergraduate Research for Doctorial Theses and Dissertations

2. Lewis, Vicky and Habershaw, Sue (1997) Interesting Ways to Supervise Student Projects, Dissertations and Theses,

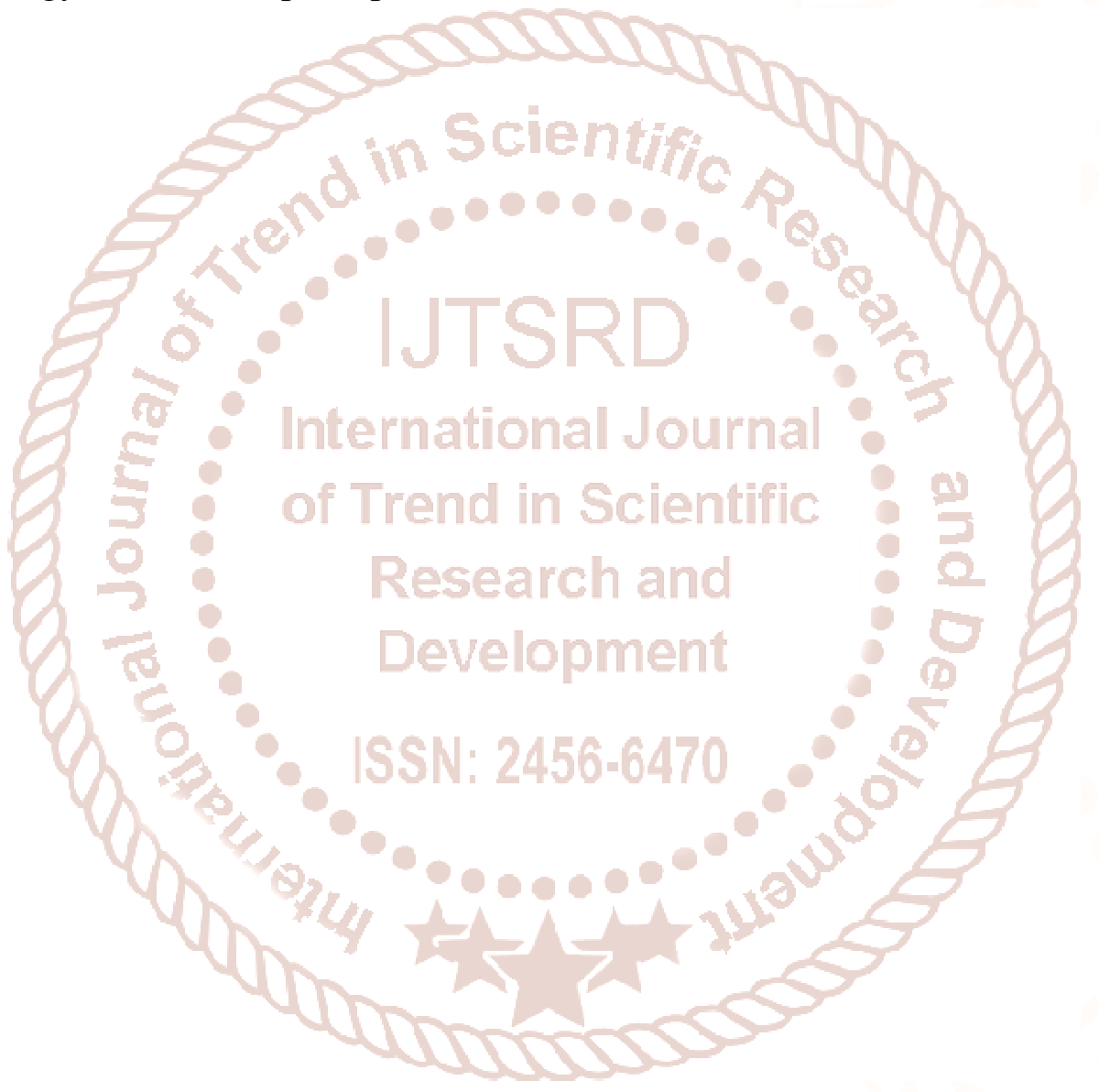

